Proceedings

\title{
Using Photos in Pedagogical and Intercultural Research with Children. Images and Research: Between Sense and Reality ${ }^{\dagger}$
}

\author{
Margherita Cardellini \\ Department of Education Studies “G.M. Bertin”, University of Bologna, 40126 Bologna, Emilia-Romagna, \\ Italy; margherita.cardellini@unibo.it \\ + Presented at the International and Interdisciplinary Conference IMMAGINI? Image and Imagination \\ between Representation, Communication, Education and Psychology, Brixen, Italy, 27-28 November 2017.
}

Published: 29 November 2017

\begin{abstract}
The international scientific literature increasingly highlights the theoretical and applicative differences between research with/on adults and research with/on children and videos, photographs and drawings are highly recommended. When a researcher chooses to use images during his/her research process, there are several ontological and epistemological problems. This paper presents some critical reflections about the use of photographs in a pedagogical and intercultural research with children, trying to focus on the potentials and limitations of this technique. A methodological instrument could also become a facilitator of intercultural education when, observing the same images, children could express different and similar perspectives.
\end{abstract}

Keywords: intercultural education; photographs; focus group; using images; children centered methods

\section{Introduction}

The international scientific literature increasingly highlights the theoretical and applicative differences between research with/on adults and research with/on children [1-5] in terms of research design, methodology, ethical questions, participations and data analysis (p. 1, [5]). As Piaget has already clarified with his theory of cognitive development, the child between 7 and 11 years old, is passing through the "concrete operational phase" where the visual/tangible elements are of primary importance to facilitate his/her potential creativity/imagination and expressivity. Therefore, in this specific range of age, it is recommended to limit abstract elements since the "formal operational phase" where the child can also use the analogical thinking [6]. This is why videos, photographs and drawings are highly recommended in the research with children [7-9]. The use of visual elements has also an evolutionary/biological explanation, that is that "the parts of the brain that process visual information are evolutionarily older than the parts that process verbal information. Thus images evoke deeper elements of human consciousness than words do; exchanges based on words alone utilize less of the brain capacity than exchanges in which the brain is processing images as well as words do" (p. 13, [10]).

The scientific literature questions the need to rethink (or not) the entire research design because of the age of the sample [11]. However, a common element among the different perspectives seems to remain the significance of visual elements as images, drawings, videos or photographs, when we realize research projects with children $[4,12,13]$. What are the potential and the critical elements (or even the limits) of the use of photographs? Although several scholars from different disciplinary perspectives seems to agree on the positivity of using visual elements, especially with children, it is also important to reflect on the relation between the participants and these "objects" and even 
the relation between these elements and the research objectives. Is it possible to control the agency of these elements? What are the potential consequences for the reliability and validity of the research project?

\section{2. "Images-Talk": Who's Really Talking? The Multi-Inter-Dialogue between Images, Researcher and Participants}

The so called "photo elicitation" is a methodological technique of research named for the first time by John Collier, photographer and anthropologist, who emphasized the use of photographs in ethnographic research [14]. "Elicitation" come from the Latin word "elicio", which means "to bring out, to extract, to evoke" (p. 375, [15]). There is the idea that photographs contain meanings, which people have the ability to see, read, interpret and share.

Of course, there are several ways to use photographs in research processes, which involve children. It is not the same to choose, as researcher, what are the "best" images to present or, for example, to ask children to select them by their own or even allowing children to take photographs with a camera [16]. Indeed, there are also important differences in terms of the subject presented on the photographs. Is he/she a person? An object? A landscape? Is he/she/it a known or unknown object or person?

To summarize, there are at least 3 levels of analysis when a researcher chooses to use photo elicitation as a technique of research:

1. Who chooses the photographs?

2. Who is the photographer?

3. What is represented on the photographs?

The answers to these questions have a great impact on the entire design project, on the relation between images and research participants and, of course on the research results.

When a researcher chooses to use images during his/her research process, there are several ontological and epistemological problems. Can we consider the "image-object" as an "objective object" only because it is given from the outside with specific and standard characteristics? Can we consider this image as a neutral element, which is universally shared on the basis of its "physical" characteristics? How do we approach this image? What kind of knowledge we produce in this human-image relation? As we can easily observe, a methodological question is quickly transformed into a philosophical one. If we admit the images' non-neutrality [17] we necessarily lose the classic scientific thinking [18].

The traditional scientific thinking is likely to be ineffective in reading and understanding phenomenon complexity. To adhere to this principle means not to give up the reliability and validity during the research process, but only to overcome its positivistic assumption, which means to overcome the idea that there is only one "correct" way to respect these two important elements of the research process. It is also important to underline that this is still a never-ending question into the scientific methodological literature, especially focused on the differences between quantitative and qualitative research [19-24]. Without getting into specifics, it is important to say that these questions have a great influence on our paper's topic in terms of paradigm, which means the way through which we look at the phenomenon. To accept complexity means not to give up to the interrelations between researcher and participants, images and researcher, participants and images, context and subjects, images and photographer and all them together. This is why the subjectivity question could become an important part of the research analysis process [25], in the knowledge that it is very difficult to have "no feelings about the issue we are researching. There is no escape from this, but it is possible to address it by turning around and reflecting upon the subjective position of the researcher" (p. 84, [26]). Gibson helps us to understand this multidirectional way to observe "things" using the word "affordance", which means "neither an objective property nor a subjective property; or it is both if you like. An affordance cuts across the dichotomy of subjective-objective and helps us to understand its inadequacy. It is equally a fact of the environment and a fact of behavior. It is both physical and psychical, yet neither. An affordance points out both ways, to the 
environment and to the observer" (p. 129). This means we do not want to deny the "real" (if we negotiate to use this term to refer to the constitutive and material parts of an object) properties of an images (i.e., colors, perspective, material, shape, etc.) but that these properties lose their meaning if we do not also consider the look of who is looking at them and the look with which they were thought, realized and choose. Choosing to use "reflexivity" as instrument-guide during the entire research process means "to bend back upon oneself". In research terms, this can be translated as thoughtful, self-aware analysis of the intersubjective dynamics between researcher and the researched. Reflexivity requires critical self-reflection of the ways in which researchers' social background, assumptions, positioning and behavior impact on the research process" (p. ix, [27]).

This premise is functional to understand what paradigm has been thought to choose the photographs used in the research project presented in the next paragraphs, which aimed to observe stereotypes and prejudices related to gender and skin color, both constructs which, as well as the concept of affordances, constantly intersect a multi-dimensional way to understand world, things and people. The aim of this paper is to show some of the possible practical implications when we choose to introduce photographs in a research project with children, trying to summarize its critical elements, using the word "critical" not to refer to something problematic or negative, but something, which questions our epistemological point of view.

\section{Children-Photopgraphs-Researcher's Relations in Qualitative Research}

Two-hundred and fifty-five children from 5 Italian primary schools were involved in this research project between November 2015 and February 2016. All the children attended the last biennium of primary school. The sample was created with an accidental procedure because of the "hot topics" involved in this research (skin color and gender), which have made difficult to obtain authorization from all the schools. Two-hundred of two-hundred and five children were born in Italy, 167/225 children had Italians parents, 18/225 children had at least one parent of foreign origin and 40/225 children had both parents of foreign origin. One-hundred ninety-five children were light-skinned and 27/225 children were dark skinned (It's important to specify that the definition of the children's skin color was assigned by the focus group moderator in accordance with the observer.). We chose to use the focus group [12,28-35] as method to analyze the co-constructed social interaction around these thematic. Each focus group was composed by no more than 7-8 children arranged in a circle with a moderator and an observer.

Once again, as already highlighted for the photograph question, we chose to listen and analyze children's words, not as completely adherent to the reality, but as mixed representations between reality, context, interaction, children perspectives and personalities.

\section{The Photographs' Choice: Why That One?}

The photograph's research was initially guided by some ideas related to a desire of homogeneity, which means the objective to find the similarities among the differences, with the knowledge that this aim was only a "problematic-tension" never completely reachable [36]. After several online research, using the most frequently used search engines, some creativity mixed with a pinch of serendipity [37-39] supported this choice, finding Angelica Dass' Humanae Project, which has significantly changed the research evolution. Humanae is a work in progress art project, which constantly grows, travelling around the world thanks to the support of common people irrespective of skin color, gender, sex, age, disabilities, etc. The aim of this project was to deconstruct our everyday code to think of skin colors, usually represented through white, black, yellow and red. The Brazilian photographer Angélica Dass chose to photograph human subject, selecting an 11 pixel square from the nose to create a skin color's background. She uses the common PANTONE scale, a technical-industrial standard, and she spread the color all around the human figure, putting at the bottom of the photograph the specific PANTONE's code as you can see in Figure 1. 


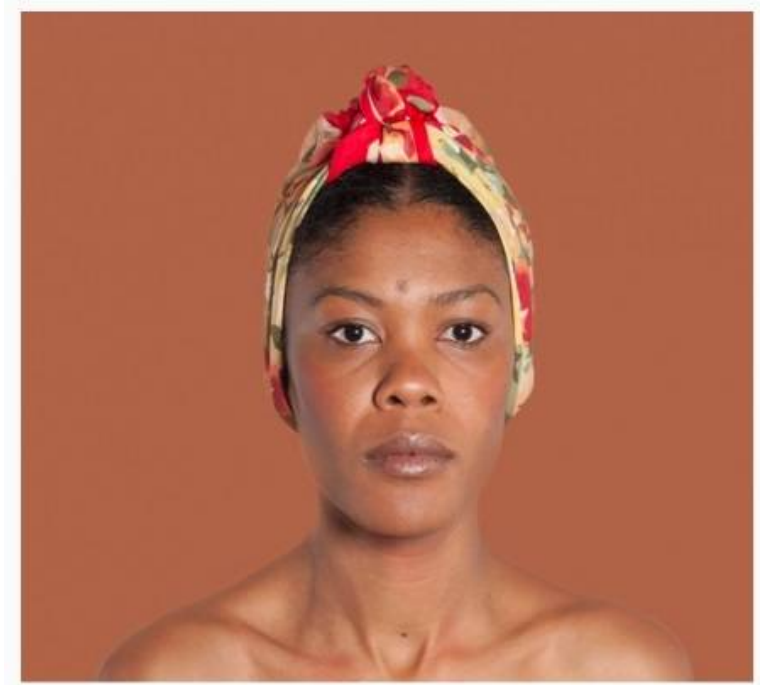

PANTONE 7522 C

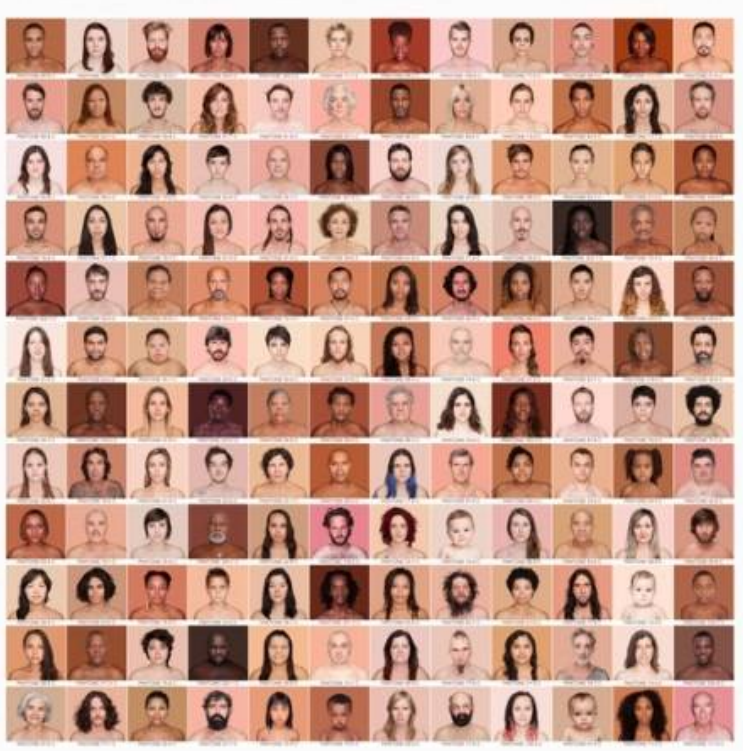

Figure 1. Angélica Dass portrait and some Humanae's photos (Humanae: https://www.google.it/ search?q=HUMANAE\&oq=humana\&aqs=chrome.0.69i59j69i60j69i57j013.893j0j4\&sourceid=chrome\& ie=UTF-8). Courtesy of Angélica Dass.

This photographic and artistic project allows us to choose among hundreds of high-quality photographs. Although the great quantity, selecting adequate pictures was not an easy task. After observing all photographs, we chose to fix some standards to facilitate the selection, trying to respond to our "homogeneity criteria" which was composed by the following standards:

1. Similar PANTONE gradation (Even if the skin color of the dark skinned people is more similar than the skin color of the light skinned people.);

2. No particular "interfering" physical characteristics (i.e., earrings, piercings, tattoos, make-up, etc.);

3. Facial expression "uniformity" (i.e., smile, eyes expression);

4. Body constitution "uniformity".

5. Age heterogeneity in the physical aspect.

The intersection between these criteria made the decision really complicated, but the most difficult standard, which has seriously limited our choice, was the first one. Observing Dass' Project is a real opportunity to be effectively aware of the thousands of shades of skin color. In Figure 2 is presented the final photographs choice.

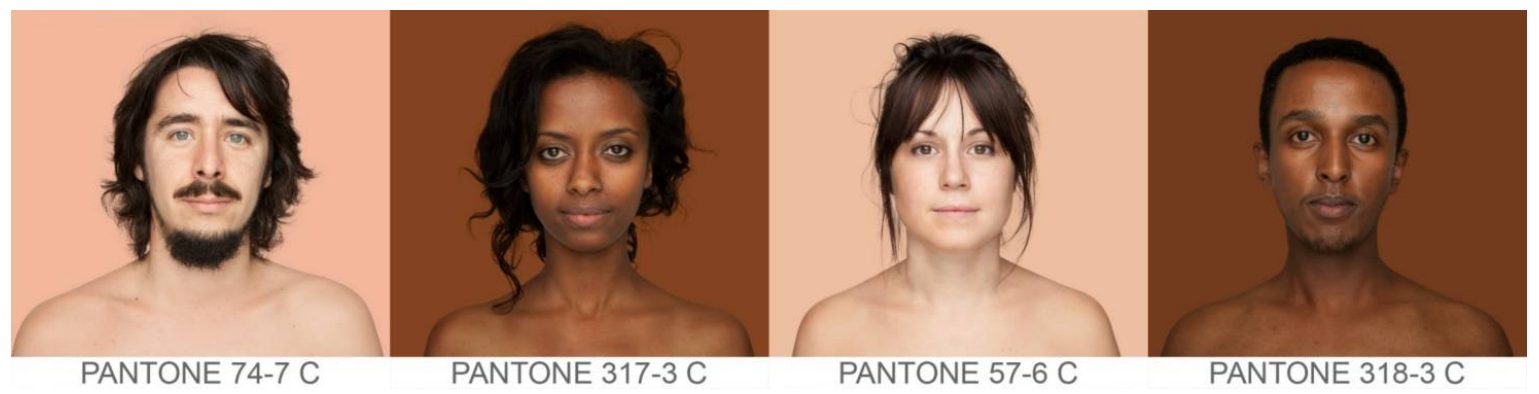

Figure 2. Final photographs choice. Courtesy of Angélica Dass.

Although the above mentioned criteria, the relation between the photos and the children unavoidably put a strain on the apparently "criteria objectivity" because the perception is always a subjective question [40,41]. As [42] highlighted: 
Once more seeking a definition of what we perceive through the physical and chemical properties of the stimuli which may act upon our sensory apparatus, empiricism excludes from perception the anger or the pain which I nevertheless read in a face, the religion whose essence I seize in some hesitation or reticence, the city whose temper I recognize in the attitude of a policeman or the style of a public building [...]. Perception thus impoverished becomes purely a matter of knowledge, a progressive noting down of qualities and of their most habitual distribution, and the perceiving subject approaches the world as the scientist approaches his experiments (pp. 27-28).

Several children identified relevant differences between the light skinned people (man and woman) and between the dark skinned people (man and woman), sometimes defining the woman as darker and other times the man (irrespective of the PANTONE code's "objectivity"). They also highlighted make-up elements in women, they found significant body weight and facial expression differences and they even assumed age differences among the subjects. Without going into details, it is interesting to notice that even this few "objective criteria" we impose into the research design become subjective as soon as they encounter children's look. Thanks to this relation, all the subjects represented by the photographs start to make alive, becoming characters with specific personalities, histories and particularities. This process is unpredictable because it is not only a static mix between photographs' elements and children's elements but is a work in progress dialogue, influenced by all the children perceptions at one time. This awareness does not mean to give up a controlled process because the impossibility to standardize every single element, instead, it means to use a "critical subjectivity" [43-45], meaning be aware of the many versions and possibilities to perceive reality as a form of "scientific gain", trying to use valid research project design able to include this complexity. Trying to include or understand complexity could be only a transcendent task, which means that as researchers we can only try to glimpse this goal. Complexity is not definable and reachable par excellence and if it was not, it would no longer be complexity. Although we cannot aspire to achieve a solution, a specific answer or result, we could follow the connections between the elements, searching for a "street of coherence". As Bateson has brilliantly quoted: "What is the pattern that connects the crab to the lobster and the primrose to the orchid, and all of them to me, and me to you?" [46].

The paradigm of complexity allows us to consider system elements and connections as part and system at the same time. Using complexity as a guide for the entire design project invites us to doubt of the variables objectivity or even calls into question the necessity to find "standards" as controlling elements. What kind of wealth of knowledge do we lose when we limit and simplify the research variables? What a risk in not to limit our research elements for the scientific knowledge? If we consider our variables as a pharmacon, which means something that is at the same time an obstacle to analyze complexity but even the only way to try to capture few of the possible connections, we could interpret our variables as flexible directions for our scientific look. In any case, for further research projects, it could be interesting to include more flexible variables and more diversity expressions (i.e.,: more skin color shades).

\section{Going beyond Gender and Skin Color: How Images Exceed Expectations}

To try to include complexity in our research project, not forgetting that the main objective was to detect gender and skin color stereotypes and prejudices, the first moderator's request was to ask children to "write on a post-it the first two things that come into your mind when you look at these people". Thanks to these words, the focus groups conversation was activated. This request produced over a thousand words, used as the starting point of our conversation. Every interpretation was very thought-provoking and it would deserve an adequate time/space for reflection. As we can easily understand this is not possible in this paper, so I choose to present you just some elements, which could represent what it means going beyond gender and skin color, that is the photo's ability to evoke and encourage conversations, which could "go beyond" the research objectives. All the words were catalogued into 3 main categories: 
1. Physical characteristics: including all the words, which refer to physical elements (i.e., eyes, sex, skin, nose, mouth, etc.).

2. Adjectives: including all the adjectives designed for any person.

3. Non-physical characteristics: including words referred to other subject's aspects (i.e., hypothesis on their job, country of origin, religion, name, etc.).

At least half of the children chose to write on his/her post-it words referred to physical characteristics. The physical characteristic most highlighted for each person represented in the photographs was:

- The beard and the moustache for the light skinned man (66 words);

- $\quad$ The skin for the dark skinned woman (70 words);

- The hair for the light skinned woman (59 words);

- The skin for the dark skinned man (63 words).

We can observe the characteristic noticed the most about the dark skinned people was the skin color, while hair and facial hair was the most observed characteristics of the light skinned people. Going beyond gender and race allows us to find other significant elements, which are related on affordances we mentioned before. For example, the "beard-moustache categories" was mostly present for the light-skinned man (maybe because of the dark skinned man seems beardless) (The beard-moustache category was present also for the dark skinned man ( 9 words).) or the words that refer to the "ears" were present only for the dark skinned man (maybe because the others' ears are quite covered by the hair). Gender words were present for all the photographs uniformly.

Referring to the "adjective words" we found that the most used adjective to refer to the light skinned man was "nice", while the most used adjective used for the dark skinned one was "sad". Indeed, for both the women represented into the photographs, the most used adjective was "beautiful".

It was interesting and stimulating trying to understand what element induced the adjectives chosen by the children using the "where do you see that?" question.

Here some examples:

Moderator: Where do you see that he is happy?

Dove lo vedi che è felice?

Annalisa (All the children's names were modified to respect their privacy.): In her mouth. In her mouth's expression.

Nella bocca. Nell'espressione della bocca (All the focus groups were conducted in Italian and translated in English, they present all the limitations of a translation. All the children's names was changed to respect their privacy.).

Moderator: Elisa, where do you see her serenity?

Elisa: In her face.

Serenità da dove lo vedi Elisa?

Dalla faccia.

Moderator: What aspect of her face?

Quale aspetto della sua faccia?

Elisa: The eyes and the mouth. She seems calm, without problems.

Gli occhi e la bocca. Sembra serena, senza problemi.

(5A-3, School 2) (This is the identifying code of the focus group.)

Finally, there are several words referred to "non-physical aspects" which, even if do not refer to physical aspects, are stimulated by their image. This inferential process produced more information than those who are immediately presented and it revealed the stereotypes and prejudices below. In particular, this category has represented the potentialities of the use of photographs because it allowed children to image about their country of origin, religion, life, job, etc. All these elements were not explicitly represented in the photographs, but they were born thanks to the encounter between children and photos. Of course, it is not possible to affirm that these aspects are only related 
to gender and skin color, because the people represented in the photographs are not only this variables, but we can also assume that these two characteristics have had an important influence.

For example, here a piece of conversation where few children discuss the possible country of origins of the dark skinned woman:

Moderator: Someone wrote ... actually two, that she's "Brazilian". (Marco and Giulio raise their hand). Marco and Giulio. Who wants to start to explain how do you think that? Where do you get that idea? Qualcuno ha scritto che potrebbe, anzi, due persone l'hanno scritto, che è "brasiliana". Marco e Giulio. Chi è che ci comincia a spiegare da dove l'ha pensato? Cosa te l'ha fatto venire in mente?

Marco: The dark skin a while, because it's neither so light nor so dark. Even if I've never seen Brazilians, I think they have a mixed skin.

Un po' per la pelle che non è né tanto bianca né tanto scura. E i brasiliani, non li ho visti, per me hanno una pelle un po' mista.

Moderator: Marco, you said that you've never seen Brazilians, but that you image they could be like that. Where did you learn that? Where did you see this? Or who told you that?

Tu dici che non li hai visti i brasiliani, ma da quello che sai tu potrebbe essere così. E dove l'hai imparato? Dove l'hai visto? O chi te l'ha detto?

Marco: My mum told me because she visited Brazil. Me l'ha detto la mamma che è andata in Brasile.

Giulio: It's the same for me. But I saw a Brazilian girl in the park whit my friends when I was little and we played with her.

Anche per me. Però io ho visto una brasiliana quando ero al parco con i miei amici e abbiamo giocato con lei anche.

Moderator: And what aspect did you remind that?

E te l'ha ricordato quale aspetto?

Giulio: The skin.

La pelle.

(5A-3, School 2)

Although in this piece of conversation we started from the country of origin to understand that the element which has elicited this thought was the skin, there were also some cases in which skin color was not mentioned at all. It's hard to say when and where skin color and gender have had a major impact at changing a conversation; sometimes this influence was visible, sometimes hidden under stereotypes and, in other cases, very nuanced and almost subtle, even (maybe) absent.

\section{Conclusions}

In this research experience, photo elicitation was used as a "ice breaker" as suggested by the research methodological literature [47-51]. If we consider this technique as a phenomenology of perception we should focus on the personal, subjective and intimate subject's look, trying to understand the process which allowed the encounter between photo and person. As Merleu-Ponty clearly states:

Objective thought is unaware of the subject of perception. This is because it presents itself with the world ready made, as the setting of every possible event, and treats perception as one of these events. For example, the empiricist philosopher considers a subject $x$ in the act of perceiving and tries to describe what happens: there are sensations, which are the subject's states or manners of being and, in virtue of this, genuine mental things. The perceiving subject is the place where these things occur, and the philosopher describes sensations and their substratum as one might describe the fauna of a distant land-without being aware that he himself perceives, that he is the perceiving subject and that perception as he lives it belies everything that he says of perception in general (p. 240, 1996) [52].

Using this paradigm helps us to be aware that even if all the children seem to observe the same photographs, they are actually seeing different words, constructing and formulating thoughts and 
images related both on the images and on themselves. Therefore every child will be carrier of a very own perception that, in a focus group context, could eventually be shared with others, maybe finding differences and similarities. In this experience of research, photo elicitation has positively influenced research process and the relationship between children and moderator/researcher because it allowed children to feel confident and competent in this particular activity as other research papers have already highlighted $[53,54]$. Empowering children to express their ideas and thoughts about photographs allows everyone to take part in the activity and, because of that, it is considered by scientific methodological literature as a "children centered research method" [55-57].

A methodological instrument could also become a facilitator of intercultural education, whereby different and similar perspectives and ideas can express themselves in a context where children can dialogue and listen to each other, respecting and tolerating others in the direction of a possible encounter [58].

\section{References}

1. Thomas, N.; O'kane, C. The ethics of participatory research with children. Child. Soc. 1998, 12, 336-348, doi:10.1111/j.1099-0860.1998.tb00090.x.

2. Christensen, P.; James, A. (Eds.) Research with Children: Perspectives and Practices; Routledge: London, UK, 2008; ISBN 075070974X.

3. Lewis, A.; Lindsay, G. (Eds.) Researching Children's Perspectives; Open University Press: Philadelphia, PA, USA, 2000; ISBN 9780335202799.

4. Punch, S. Research with children: The same or different from research with adults? Childhood 2002, 9, 321341, doi:10.1177/0907568202009003005.

5. Eder, D.; Fingerson, L. Interviewing children and adolescents. Handb. Interview Res. Context Method 2002, 1, 181-203.

6. Piaget, J.; Zamorani, E. Lo Sviluppo Mentale del Bambino e Altri Studidi Psicologia; Einaudi: Torino, Italy, 1967; ISBN 8806155261.

7. Young, L.; Barrett, H. Adapting visual methods: Action research with Kampala street children. Area 2001, 33, 141-152, doi:10.1111/1475-4762.00017.

8. Thomson, P. (Ed.) Doing Visual Research with Children and Young People; Routledge: London, UK, 2009; ISBN 9780415431101.

9. Literat, I. "A pencil for your thoughts": Participatory drawing as a visual research method with children and youth. Int. J. Qual. Methods 2013, 12, 84-98, doi:10.1177/160940691301200143.

10. Harper, D. Talking about pictures: A case for photo elicitation. Vis. Stud. 2002, 17, 13-26, doi:10.1080/14725860220137345.

11. Tisdall, K.; Davis, J.M.; Gallagher, M. Researching with Children and Young People: Research Design, Methods and Analysis; Sage: Los Angeles, CA, USA, 2008; ISBN 9781412923897.

12. McDonald, W.J.; Topper, G.E. Focus-group research with children: A structural approach. Appl. Mark. Res. 1998, 28, 3-11.

13. Kirova, A.; Emme, M. Fotonovela as a research tool in image-based participatory research with immigrant children. Int. J. Qual. Methods 2008, 7, 35-57, doi:10.1177/160940690800700203.

14. Collier, J., Jr. Photography in anthropology: A report on two experiments. Am. Anthropol. 1957, 59, 843859, doi:10.1525/aa.1957.59.5.02a00100.

15. Castiglioni, L.; Mariotti, S. Vocabolario Della Lingua Latina; Loescher: Bologna, Italy, 1996.

16. Smith, F.; Barker, J. Contested spaces: Children's experiences of out of school care in England and Wales. Childhood 2000, 7, 315-333, doi:10.1177/0907568200007003005.

17. Damisch, H. Five notes for a phenomenology of the photographic image. October 1978, 5, 70-72, doi:10.2307/778645.

18. Morin, E. La Conoscenza Della Conoscenza; Feltrinelli: Milano, Italy, 1993; ISBN 9788807080760.

19. Kirk, J.; Miller, M.L. Reliability and Validity in Qualitative Research; Sage: Los Angeles, CA, USA, 1986; ISBN 9780803924703.

20. Guba, E.G.; Lincoln, Y.S. Competing paradigms in qualitative research. In Handbook of Qualitative Research; Denzin, N.K., Lincoln, Y.S., Eds.; Sage: Los Angeles, CA, USA, 1994; Volume 2, pp. 163-194.

21. Morse, J.M; Barret, M.; Mayan, M.; Olson, K.; Spiers, J. Verification strategies for establishing reliability and validity in qualitative research. Int. J. Qual. Methods 2002, 1, 13-22, doi:10.1177/160940690200100202. 
22. Golafshani, N. Understanding reliability and validity in qualitative research. Qual. Rep. 2003, 8, 597-606.

23. Denzin, N.K.; Lincoln, Y.S. The Sage Handbook of Qualitative Research; Sage: Losa Angeles, CA, USA, 2011; ISBN 1412974178.

24. Silverman, D. Qualitative Research; Sage: Los Angeles, CA, USA, 2016; ISBN 1473916569.

25. Finlay, L. "Outing” the researcher: The provenance, process, and practice of reflexivity. Qual. Health Res. 2002, 12, 531-545, doi:10.1177/104973202129120052.

26. Parker, I. Qualitative Data and the Subjectivity of 'Objective' Facts; Statistics in Society: The Arithmetic of Politics; Arnold: London, UK, 1999.

27. Finlay, L.; Gough, B. Reflexivity: A Practical Guide for Researchers in Health and Social Sciences; John Wiley \& Sons: USA, 2008; ISBN 978-0-632-06414-4.

28. Morgan, D.L.; Scannell, A.U. Planning Focus Groups; Sage: Los Angeles, CA, USA, 1998; ISBN 076190817X, 9780761908173.

29. Vaughn, S.; Schumm, J.S.; Sinagub, J.M. Focus Group Interviews in Education and Psychology; Sage: Los Angeles, CA, USA, 1996; ISBN 978080395893.

30. Migliorini, L.; Rania, N. I focus group-uno strumento per la ricerca qualitativa. Animazione Soc. 2001, 2, 82-88.

31. Kennedy, C.; Kools, S.; Krueger, R. Methodological considerations in children's focus groups. Nurs. Res. 2001, 50, 184-187, doi:10.1097/00006199-200105000-00010.

32. Zammuner, V.L. I Focus Group; Società Editrice Il Mulino: Bologna, Italy, 2003; ISBN 9788815084941.

33. Albanesi, C. I Focus Group; Carocci: Roma, Italy, 2004; 9788843031948.

34. Gibson, J.E. Interviews and focus groups with children: Methods that match children's developing competencies. J. Fam. Theory Rev. 2012, 4, 148-159, doi:10.1111/j.1756-2589.2012.00119.x.

35. Krueger, R.A.; Casey M.A. Focus Groups: A Practical Guide for Applied Research; Sage Publications: Los Angeles, CA, USA, 2014; ISBN 1483365247.

36. Contini, M. Categorie e percorsi del problematicismo pedagogico. Ricerche di Pedagogia e Didattica 2006, 1, 51-65.

37. Merton, R.K.; Barber, E.G. Viaggi e Avventure Della Serendipity; Il Mulino: Bologna, Italy, 2002; ISBN 9788815063328.

38. Bruno, F. L'intuizione Nella Ricerca Scientifica: Breve Percorso fra Metodo, Creatività e Serendipity. In La Creatività-Dote Individuale o Prodotto Sociale? Quadrio, A., Puggelli, F.R., Eds.; ISU Università Cattolica: Milano, Italy, 2003; pp. 193-208, ISBN 9788883112416.

39. Lupo, L. Filosofia Della Serendipity; Guida Editori: Napoli, Italy, 2012; ISBN 9788866661788.

40. Mulaik, S.A.; James, L.R. Objectivity and Reasoning in Science and Structural Equation Modeling. In Structural Equation Modeling: Concepts, Issues and Applications; Hoyle, R., Ed.; Sage: Thousand Oaks, CA, USA, 1995; ISBN 0803953186.

41. Crary, J. Suspensions of Perception; MIT: Cambridge, UK, 2001; ISBN 9780262531993.

42. Merleau-Ponty, M. Phenomenology of Perception; Taylor and Francis: UK/USA, London/New York 2005; ISBN 0203994612.

43. Bateson, G. Steps to an Ecology of Mind: Collected Essays in Anthropology, Psychiatry, Evolution, and Epistemology; University of Chicago Press: Chicago, IL, USA, 1972; ISBN 9789507247002.

44. Reason, P.; Rowan, J. (Ed.) Human Inquiry: A Sourcebook of New Paradigm Research; Wiley: Chichester, UK, 1981; ISBN 9780471279365.

45. Keller, E.F. Reflections on Gender and Science; Yale University Press: New Haven, CT, USA, 1985; ISBN 9780300036367.

46. Bateson, G. Mind and Nature: A Necessary Unity; Dutton: New York, NY, USA, 1979; ISBN 9780553137248.

47. Tammivaara, J.; Enright, D.S. On eliciting information: Dialogues with child informants. Anthropol. Educ. Q. 1986, 17, 218-238, doi:10.1525/aeq.1986.17.4.04x0616r.

48. Clark, C.D. The autodriven interview: A photographic viewfinder into children's experience. Vis. Stud. 1999, 14, 39-50, doi:10.1080/14725869908583801.

49. Horstman, M.; Bradding, A. Helping children speak up in the health service. Eur. J. Oncol. Nurs. 2002, 6, 75-84, doi:10.1054/ejon.2002.0185.

50. Rasmussen, K. Places for children-children's places. Childhood 2004, 11, 155-173, doi:10.1177/0907568204043053. 
51. Cappello, M. Photo interviews: Eliciting data through conversations with children. Field Methods 2005, 17, 170-182, doi:10.1177/1525822X05274553.

52. Merleau-Ponty, M. op. cit., 1996; ISBN 0415834333.

53. Epstein, I.; Stevens, B.; McKeever, P.; Baruchel, S. Photo elicitation interview (PEI): Using photos to elicit children's perspectives. Int. J. Qual. Methods 2006, 5, 1-11, doi:10.1177/160940690600500301.

54. Whiting, L.S. Reflecting on the use of photo elicitation with children. Nurse Res. 2015, 22, 13-17, doi:10.7748/nr.22.3.13.e1283.

55. Barker, J.; Weller, S. "Is it fun?" Developing children centred research methods. Int. J. Sociol. Soc. Policy 2003, 23, 33-58, doi:10.1108/01443330310790435.

56. Einarsdottir, J. Playschool in pictures: Children's photographs as a research method. Early Child Dev. Care 2005, 175, 523-541, doi:10.1080/03004430500131320.

57. Mitchell, L.M. Child-centered? Thinking critically about children's drawings as a visual research method. Vis. Anthropol. Rev. 2006, 22, 60-73, doi:10.1525/var.2006.22.1.60.

58. Genovese, A. Per una pedagogia interculturale. Dalla Stereotipia Dei Pregiudizi All'impegno Dell'incontro; Bononia University Press: Bologna, Italy, 2003; ISBN 9788873950189.

(C) 2017 by the authors. Licensee MDPI, Basel, Switzerland. This article is an open access article distributed under the terms and conditions of the Creative Commons Attribution (CC BY) license (http://creativecommons.org/licenses/by/4.0/). 